\title{
Combination of $\mathrm{H} 120$ and 1/96 avian infectious bronchitis virus vaccine strains protect chickens against challenge with IS/1494/06 (variant 2)-like infectious bronchitis virus
}

\author{
M. HABIBI ${ }^{1}$, V. KARIMI ${ }^{1}$, A. G. LANGEROUDI ${ }^{2}$, S. A. GHAFOURI ${ }^{3}$, M. HASHEMZADEH ${ }^{4}$, \\ R. K. FARAHANI ${ }^{3}$, H. MAGHSOUDLOO ${ }^{3}$, H. ABDOLLAHI ${ }^{3}$, P. SEIFOURI ${ }^{3}$
}

\begin{abstract}
${ }^{1}$ Department of Clinical Sciences, Faculty of Veterinary Medicine, University of Tehran, Tehran, Iran; ${ }^{2}$ Department of Microbiology and Immunology, Faculty of Veterinary Medicine, University of Tehran, Tehran, Iran; ${ }^{3}$ Iranian Veterinary Organization, Tehran, Iran; ${ }^{4}$ Research and Production of Poultry Viral Vaccine, Razi Vaccine and Serum Research Institute, Karaj, Iran
\end{abstract}

\begin{abstract}
Summary. - Avian infectious bronchitis (IB) is a worldwide chicken disease, caused by avian infectious bronchitis virus (IBV) which infects all commercial poultry lines. The present study was done to evaluate protection caused by two different serotype vaccines (Massachusetts and 793/B) in order to evaluate protection against challenge with IS/1494/06-like virus (variant 2-like virus), which is prevalent in the Middle East. SPF chickens were divided into four groups $(n=20)$. First and second group as negative control group and non-vaccinated-challenged group received no vaccine. Groups 3 and 4 received H120-H120 and H120-1/96 IBV vaccine strains at the $1^{\text {st }}$ and $14^{\text {th }}$ day, respectively. Twenty one days after last vaccination, non-vaccinatedchallenged group and vaccinated group were challenged using variant 2 -like IBV. Serum samples were collected before challenge to measure humoral immune response of chickens. Five days after challenge, the tissue samples from the trachea, lungs and kidneys were taken to evaluate cilliary activity, viral load (quantitative real-time RT-PCR), and histopathological evaluation. Clinical sign scores were also recorded after challenge. Overall, the results showed a protective efficacy of the used vaccination program. Best cross protection (69.2\%) was obtained in the H120-1/96 vaccinated group. Virus replication of the challenged virus in H120-1/96 group compared with H120-H120 group showed a significant reduction of viral load in trachea (1.5 $\times 10^{3}$ compared to 503$)$ and kidneys. Clinical sign scores of the challenged groups showed significant effect of the vaccination program to reduce clinical signs. The trachea pathological scores and histopathological findings in the lungs and kidneys also confirmed better protective efficacy of vaccinated groups. In conclusion, using combination of heterologous IBV vaccine serotypes (Massachusetts and 793/B) would be a better strategy to control variant 2-like viruses, but more evaluation is needed using other circulating isolates to find the best combination of vaccines.
\end{abstract}

Keywords: avian infectious bronchitis; vaccination; cross protection; 1/96 strain

\section{Introduction}

Infectious bronchitis virus (IBV) is a major cause of economic losses in poultry industry and can be involved

*Corresponding author. E-mail: arashghalyanchi@gmail.com; ghalyana@ut.ac.ir; phone: +9821-61117154.

Abbreviations: GMT = geometric mean titer; IB = infectious bronchitis; IBV = infectious bronchitis virus; Mass = Massachusetts serotype; $\mathrm{SPF}=$ specific pathogen free in respiratory diseases, nephritis, and poor egg production and quality.

IBV is the coronavirus of the domestic fowl that is mainly observed in chickens. It possesses a positive sense single-stranded RNA genome that ranges from 27 to $31 \mathrm{~kb}$ (Cavanagh, 1996). The Coronaviridae family is classified into four groups: alpha coronavirus, beta coronavirus, gamma coronavirus, and delta coronavirus. IBV belongs to the gamma coronaviruses (Cavanagh, 2005). IBV genome encodes several viral proteins which play important antigenic and 
immunogenic roles in the virus structure. Spike (S) antigen, which is known as main immunogenic antigen of IBV, has two subunits, S1 and S2. The S1 subunit, which is the most variable part, is responsible for viral variations and recombination. There are hundreds of IBV serotypes and the majority of them differ from each other by 20 to $25 \%$ of amino acids of subunit S1 (Cavanagh et al., 1997b; Jackwood et al., 2001), however, some serotypes differ approximately by up to $50 \%$ of amino acids (Bande et al., 2015). The S1 subunit of the $S$ protein is the main inducer of protective immunity and it carries majority of the virus neutralizing epitopes, including serotype-specific epitopes, which are usually conformationdependent in nature (Mockett et al., 1984). New variant strains may differ as much as 55\% in their S1 amino acid sequences compared with vaccine strains (Gelb Jr et al., 2005; Kusters et al., 1989). Many new variants have been isolated from commercial flocks (Jackwood, 2012; Sjaak de Wit et al., 2011). Considering the level of homology of S1 gene and the level of cross-protection, it has been shown in several studies that there is a higher chance of cross-protection between strains with a high level of homology than strains with low homology (Cavanagh et al., 1997b). However, the results indicate that this latter relationship is rather weak (De Wit et al., 2011). There is a significant drop in cross-protection in some strains which differ in only a few percents of the genome sequence (De Wit et al., 2012), whereas, there is a high level of cross-protection against other strains with lower homology. The continual emergence of the new IBV serotypes worldwide necessitates prudent evaluation of the level of cross-protection achieved by the use of currently available IBV vaccines (Gelb Jr et al., 1991). As it is expected, cross-protection tends to diminish as the degree of amino acid identity between the S1 proteins of the two IBV strains decreases (Cavanagh et al., 1997a). Revaccination using a different serotype can lead to protection against a broader range of serotypes (Raj and Jones, 1996). Some strains of the IBV are able to induce cross-protection against other genotypes, and these are considered as protectotypes. Protectotypes have been suggested as a valuable approach to develop IBV infection control strategies (Raj and Jones, 1996). In Iran, several genotypes of IBV have been reported (Akbari Azad et al., 2007; Ghahremani et al., 2011). The first isolation of IBV Massachusetts (Mass) serotype in Iranian chicken flocks was reported by Aghakhan et al. (1994). Later, several Iranian researchers identified the 793/B serotype (Akbari Azad et al., 2007). The 793/B serotype is regarded as one of the dominant IBV genotypes circulating in Iran (Seyfi Abad Shapouri et al., 2004). Also, the presence of variant 2 viruses (IS/1494/06like) in Iranian commercial flocks have been demonstrated (Hosseini et al., 2015). The isolation of IS/1494/06 one of the Israeli variant 2 isolates and information on its S1 gene sequence in GenBank (Acc. No. EU780077) has first been reported by Meier and Maher from Israel (Meir et al., 2004).
The IS/1494/06 is still a major IBV variant in Israel, Jordan, Egypt, Turkey and other countries in the Middle East (Hosseini et al., 2015; Hussein et al., 2014; Kahya et al., 2013). IS/1494/06 is known to be nephropathogenic and it also affects the respiratory system (Susan et al., 2010). It should be noted that several Mass and 793/B vaccines have been used in Iran since first isolation of IB viruses. IBV strain 1/96 has been isolated first in Hungary and commercialized by Ceva Santé Animale with trade name "IBird". In this study, we aimed to evaluate cross-protection induced by vaccination using combination of Mass (H120) and 793/B (1/96 strain) against IS/1494 (variant 2) genotype.

\section{Materials and Methods}

Experimental design. White specific pathogen-free (SPF) leghorn chickens were divided into four groups containing 20 birds each. Each group in all experiments was housed in a separate negative pressure isolators. They were provided with food and water ad libitum. Groups were vaccinated and challenged as shown in Table 1 . One and 14 days old chickens were vaccinated with Mass (H120; Ceva Santé Animale) and 793/B vaccines (1/96; IBird, Ceva Santé Animale), respectively using an eye drop. After 35 days, birds in groups 2 (non-vaccinated-challenged group), 3 (H120-H120) and 4 (H120-1/96) were challenged using nasal route $\left(10^{4} \mathrm{EID}_{50}\right)$. Before the challenge, sera samples were taken from the birds to evaluate ELISA titers of IBV vaccination using IDEXX kit (IDEXX Laboratories, Inc., USA). Clinical signs were recorded for five days after challenge in order to evaluate the clinical scores for each group. Five days after challenge, samples were taken from trachea, lungs and kidneys for histopathology, quantitative real-time RT-PCR and cilliary activity of trachea.

Challenge strain history. Tissue samples from trachea and kidneys were collected from chickens showing clinical signs suspected to be related to the IB. Samples were taken from vaccinated flocks from eight Iran provinces. For virus isolation, homogenized samples were inoculated into the allantoic cavity of 9-11 days old SPF embryonated eggs. Primary diagnostics of IBV was done using PCR assay with the target of 5'-UTR part of IBV genome. For genotyping, positive samples were submitted to a nested RT-PCR reaction amplifying S1 gene. Based on genotyping and molecular epidemiology, the IS/1494/06 (variant 2-like) virus was identified as a dominant genotype. From about forty variant 2-like isolates, one was selected at the fifth egg passage level. It was shown to be free from contamination by other avian pathogens such as Newcastle disease virus, avian influenza virus, infectious laryngotracheitis virus, reoviruses, mycoplasma, and other bacteria using molecular detection methods and cultivation. The S1 sequence of the challenge 
virus was submitted to the NCBI (Acc. No. KR869776). EID was calculated by Reid-Muench method.

Antibody response. The humoral immune response (geometric mean titer: GMT) of birds against IBV before the challenge was measured by ELISA (IDEXX).

Ciliostasis test. Assessment of protection against challenge in each experiment was evaluated using ciliostasis test (Cook et al., 1976). Five days post-challenge, all of the chickens in each group were euthanized. The tracheas were carefully removed and examined for ciliary activity as described previously (Cavanagh et al., 1997b). Briefly, each of 10 tracheal rings ( 3 rings of upper, 4 rings of middle and 3 rings of lower trachea) were examined by low-power microscopy and ciliary activity was evaluated as follows: $0=$ all cilia beating; $1=75 \%$ beating; $2=50 \%$ beating; $3=25 \%$ beating; and $4=$ none beating ( $100 \%$ ciliostasis). This gave a maximum possible ciliostasis score of 40 in case of complete ciliostasis (total lack of protection).

Clinical observations. Clinical signs resulting from IBV challenge were registered daily till 5 days post challenge, according to their severity as $0=$ normal breathing can be heard, $1=$ slight/rare tracheal rales can be heard after provoking by moving the chick, 2 = moderate/frequent tracheal rales can be heard without moving the chick, but not continuously and $3=$ marked, continuous tracheal rales can be heard.

Histopathology. Tracheal, lung and kidney samples, taken 5 days after challenge (40 days), were fixed in buffered formalin (10\%), processed, sectioned, and stained with hematoxylin and eosin for histopathological evaluation of the lesions produced by the challenge virus. The tracheal lesions were scored from 1 to 4 based on the severity of the observed lesions: 1 = no lesions, 2 = moderate epithelial hyperplasia and subepithelial lymphoid infiltrates, $3=$ sever epithelial hyperplasia and subepithelial lymphoid infiltrate described in previous studies (Chen et al., 1996; Nakamura et al., 1991).

$R N A$ extraction, $c D N A$ synthesis and quantitative real-time $P C R$. Viral RNA was isolated from tissues using Cinna Pure RNA extraction kit (Sinaclone, Iran) according to the sup-

Table 1. Experimental schedule of vaccination using Massachusetts and 793/B-like IBV vaccines and challenge with IS/1494-like IBV 21 days post vaccination

\begin{tabular}{llccc}
\hline $\begin{array}{l}\text { Group } \\
\text { No. }\end{array}$ & Names of groups & Day 1 & Day 14 & $\begin{array}{c}\text { Challenge } \\
\text { (day 35) }\end{array}$ \\
\hline 1 & Negative control & - & - & - \\
2 & $\begin{array}{l}\text { Non-vaccinated- } \\
\text { challenged group }\end{array}$ & - & - & + \\
3 & H120-H120 & $\begin{array}{c}\text { H120 } \\
\text { (Ceva) }\end{array}$ & H120 (Ceva) & + \\
4 & H120-1/96 & $\begin{array}{c}\text { H120 } \\
\text { (Ceva) }\end{array}$ & $\begin{array}{c}\text { IBird-1/96 } \\
\text { (Ceva) }\end{array}$ & + \\
\hline
\end{tabular}

Table 2. Clinical scores, tracheal pathological scores and ELISA titers of groups receiving different vaccination and challenge scheme (evaluation was conducted 5 day post challenge)

\begin{tabular}{llccc}
\hline $\begin{array}{l}\text { Group } \\
\text { No. }\end{array}$ & Names of groups & $\begin{array}{c}\text { Median } \\
\text { clinical } \\
\text { scores }\end{array}$ & $\begin{array}{c}\text { Median tracheal } \\
\text { pathological } \\
\text { scores }\end{array}$ & $\begin{array}{c}\text { ELISA } \\
\text { titers }\end{array}$ \\
\hline 1 & $\begin{array}{l}\text { Negative control } \\
\text { Non-vaccinated- } \\
2\end{array}$ & 0 & 1 & 0 \\
3 & $\begin{array}{l}\text { challenged group } \\
\text { H120-H120 }\end{array}$ & 0 & 3 & 0 \\
4 & H120-1/96 & 0 & 2 & 1064 \\
\hline
\end{tabular}

*Antibody titers against IBV were measured before challenge.

pliers' instructions. cDNA was synthesized using RevertAid first strand cDNA synthesis kit (Thermo Scientific, Canada). Real-time PCR for IBV detection based on 5' UTR was used in this study. Real-time PCR amplification was done with the amplification kit (Bioneer, South Korea) with forward primer (5'-GCTTTTGAGCCTAGCGTT-3') and reverse primer (5'-GCCATGTTGTCACTGTCTATTG-3'), and Taqman dual-labeled probe (FAM-CACCACCAGAACCTGTCA CCTC-BHQ1) (Callison et al., 2006). PCR cycling parameters were $95^{\circ} \mathrm{C}$ for $2 \mathrm{~min}$, then 40 cycles of $95^{\circ} \mathrm{C}$ for $15 \mathrm{~s}$ and $60^{\circ} \mathrm{C}$ for $1 \mathrm{~min}$. The reaction was carried out in a QIAGEN Rotor-Gene Q (Corbett Rotor Gene 6000, USA).

Statistical analysis. To evaluate and compare the clinical scores, tracheal pathological scores and ciliostasis between the groups, Mann-Whitney test using SPSS 12.1 software

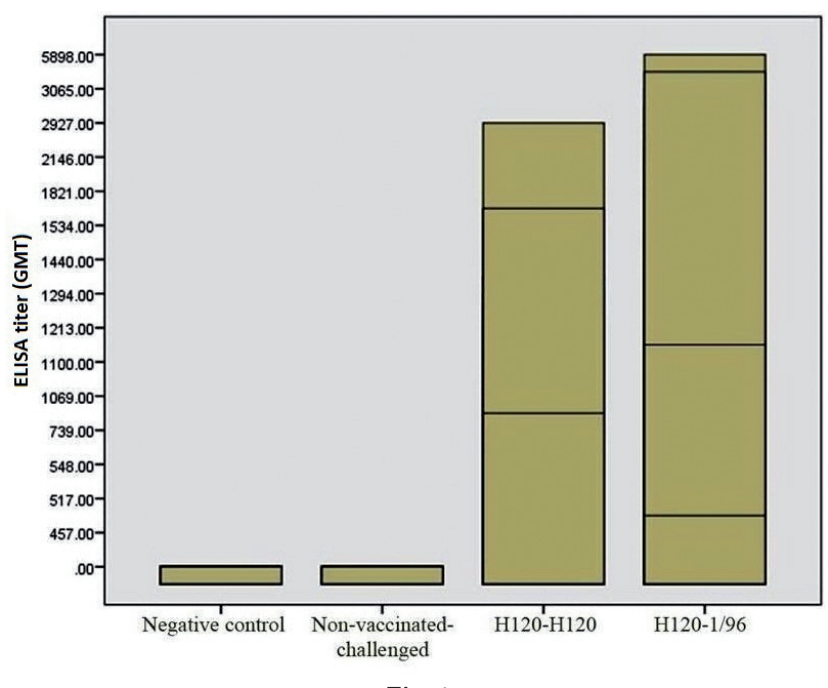

Fig. 1

Comparison of antibody response of vaccinated groups to IBV Significant differences $(\mathrm{P}<0.05)$ were observed between vaccinated groups with higher response seen on $\mathrm{H} 120-1 / 96$ vaccinated group. 


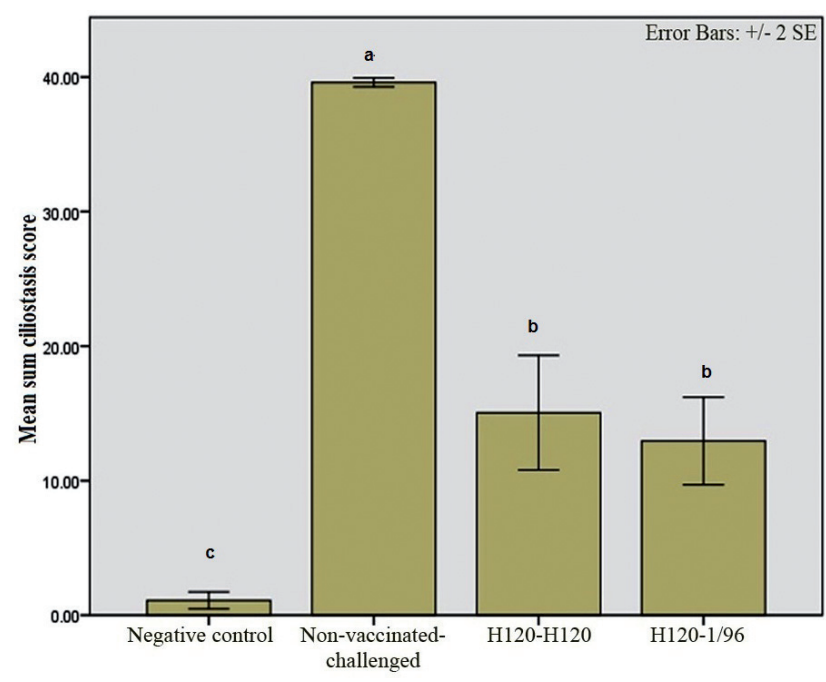

Fig. 2

Mean ciliostasis scores

Significant differences $(\mathrm{P}<0.05)$ were observed between vaccinated $(\mathrm{H} 120$ H120 and H120-1/96 group) and non-vaccinated-challenged group (a,b,c).

was used. The 0.02 level was considered as significant. Antibody results were compared using Student's $t$-test. Finally, one-way ANOVA with significance level of 0.05 was used to compare virus loads.

\section{Results}

\section{IBV antibody detection}

To evaluate vaccination program effect on immune system response the titers of antibody against IBV were detected using ELISA method. As expected, no antibody was detected in non-vaccinated-challenged group and negative control group (Table 2). The results showed significant differences $(\mathrm{P}<0.05)$ between H120-H120 (GMT: 1064) and H120-1/96 (GMT: 1960) groups using t-test analytical method (Fig. 1).

\section{Ciliostasis test}

To measure the effect of a virus on the tracheal mucosa we have used the ciliostasis test. The results between groups were compared using Mann-Whitney test based on median ciliary activity score of every bird. Comparing groups in twotailed comparison showed a significant difference $(\mathrm{P}<0.02)$ between non-vaccinated-challenged group and H120-H120 vaccinated and challenged group. The same results were obtained by comparison of non-vaccinated-challenged group and $\mathrm{H} 120-1 / 96$ vaccinated and challenged group $(\mathrm{P}<0.02)$. On the other hand, there were no significant differences

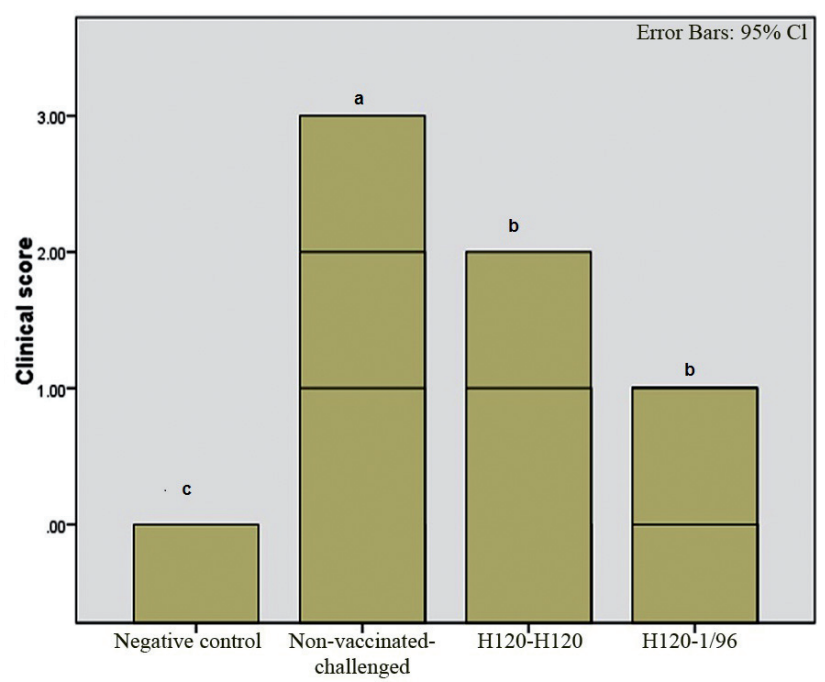

Fig. 3

Clinical signs scores

Significant differences $(\mathrm{P}<0.05)$ were observed between vaccinated groups (group 3: H120-H120 and group 4: H120-1/96) and non-vaccinatedchallenged group (group 2) (a,b,c).

comparing H120-H120 and H120-1/96 groups based on ciliostasis score. Percentage of cross protection obtained by vaccination of $\mathrm{H} 120-\mathrm{H} 120$ and $\mathrm{H} 120-1 / 96$ groups was $60 \%$ and $69.2 \%$, respectively (Fig. 2).

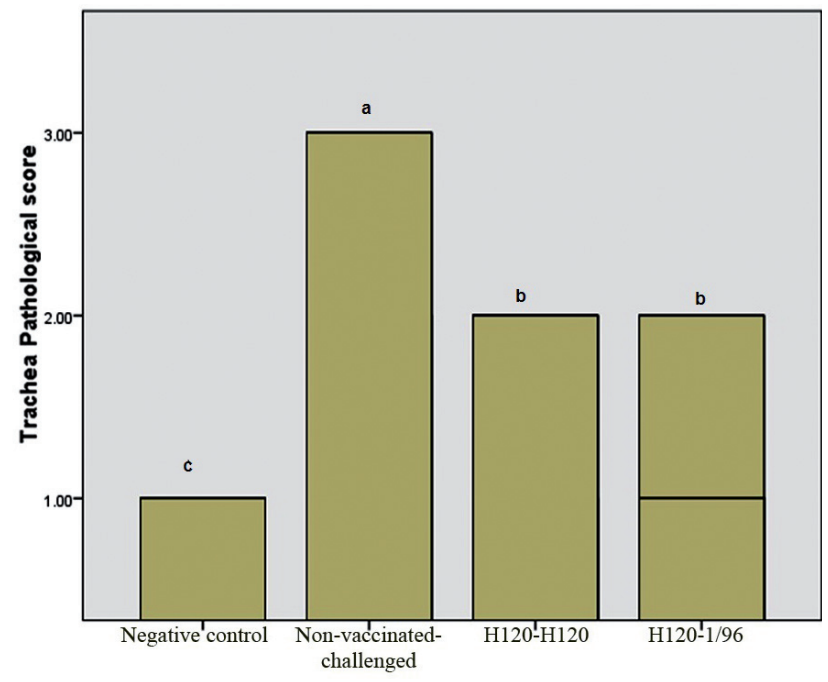

Fig. 4

Tracheal pathological scores

Median tracheal pathological score was significant $(\mathrm{P}<0.05)$ between non-vaccinated-challenged to $\mathrm{H} 120-\mathrm{H} 120$, non-vaccinated-challenged to H120-1/96, negative control to non-vaccinated-challenged and negative control to H120-H120 groups. Not significant $(\mathrm{P}>0.05)$ differences were detected between $\mathrm{H} 120-\mathrm{H} 120$ and $\mathrm{H} 120-1 / 96$ groups and between negative group and group 4 . 

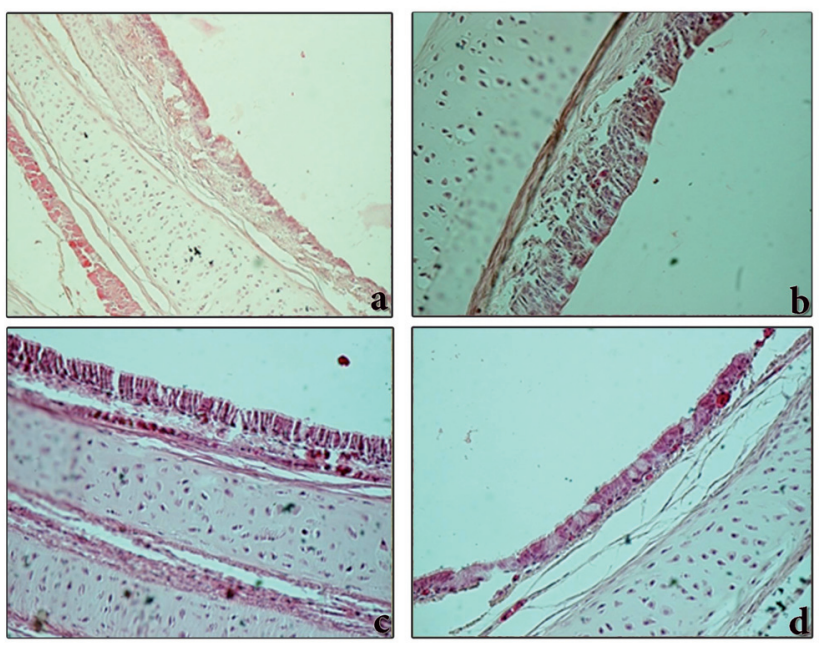

Fig. 5

Histopathology of the trachea

Microscopic changes of the hematoxylin and eosine stained trachea in the SPF chickens infected with IS/1484-like IBV isolate after 5 days post challenge. Negative control group (a); tracheal lesions of non-vaccinatedchallenged group receiving challenge virus and non-vaccinated group (b); H120-H120 vaccinated-challenge group showing less lesions (c); nonvaccinated-challenged group, and trachea with almost no changes obtained from H120-1/96 vaccinated-challenged group (d).

\section{Clinical signs score}

Clinical observations were recorded and scored from 5 days post challenge. The results of clinical scores are shown in Fig. 3. There were significant differences $(\mathrm{P}<0.05)$ between non-vaccinated-challenged group (median score 1.5) vs. H120-H120 (median score 0) group and non-vaccinatedchallenged group vs. H120-1/96 (median score 0) group. There was no significant difference between H120-H120 and H120-1/96 groups (Table 2).

\section{Tracheal pathological scores}

Based on pathological findings in trachea using scoring method, described previously, all challenged groups were compared two by two with negative control (not vaccinated-not challenged) group. Significant differences were observed comparing non-vaccinated-challenged group (median score 3 ) and H120-H120 group (median score 2) with negative control group (median score 1) indicating meaningful pathologic lesion scores $(\mathrm{P}<0.05)$ (Table 2). No significant results were detected between negative control and H120-1/96 groups (median score 1) indicating proper protection level (Fig. 4). A significant difference was observed by comparing non-vaccinated-challenged group vs. H120-H120 group and non-vaccinated-challenged group vs. H120-1/96 group ( $\mathrm{P}<0.05)$, but no significant level was observed between H120-H120 and H120-1/96 groups (Fig. 5).

\section{Histopathological evaluation}

Histopathological assessment of lungs between challenged groups showed a relative protection in the vaccinated groups.
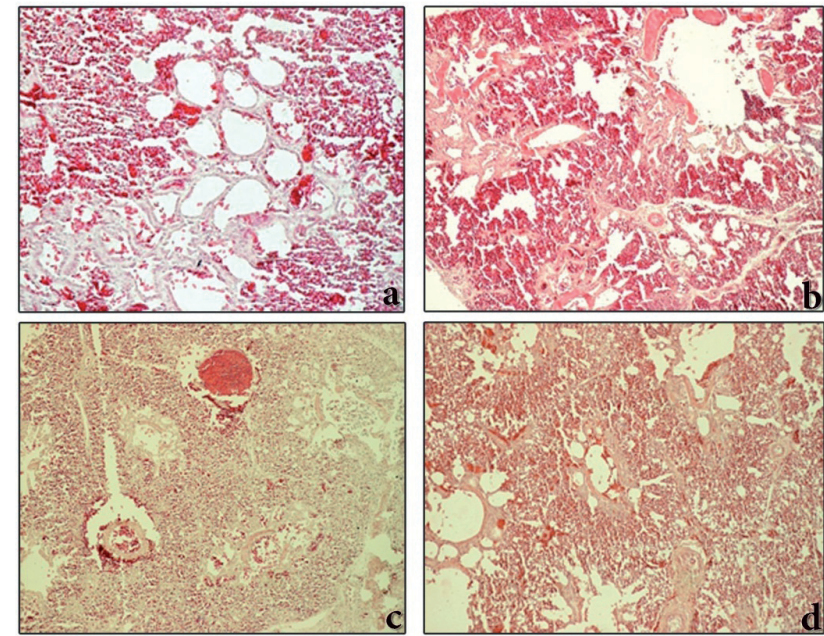

Fig. 6

\section{Histopathology of lungs}

Microscopic changes of the hematoxylin and eosine stained lungs in the SPF chickens infected with IS/1484-like IBV isolate after 5 days post challenge. Lungs of control group (a); lungs of non-vaccinated-challenged group with hyperemia petechia, and infiltration of inflammatory cells $(\mathbf{b})$; H120-H120 group showing mild hyperemia (c); H120-1/96 group with mild hyperemia (d).
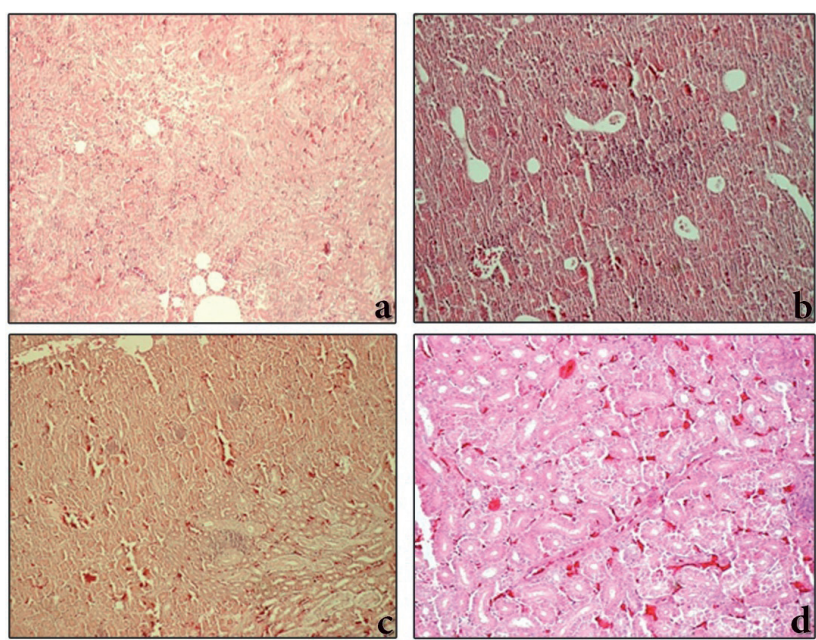

Fig. 7

Histopathology of kidneys

Microscopic changes of the hematoxylin and eosine stained kidneys in the SPF chickens infected with IS/1484-like IBV isolate after 5 days post challenge. Normal histological view of kidneys in control group (a); infiltration of inflammatory cells to interstitial tissue along with hyperemia and petechiae in non-vaccinated-challenged group (b); mild hyperemia and no lesions in H120-H120 group (c), mild hyperemia and no lesions in H120-1/96 group (d). 


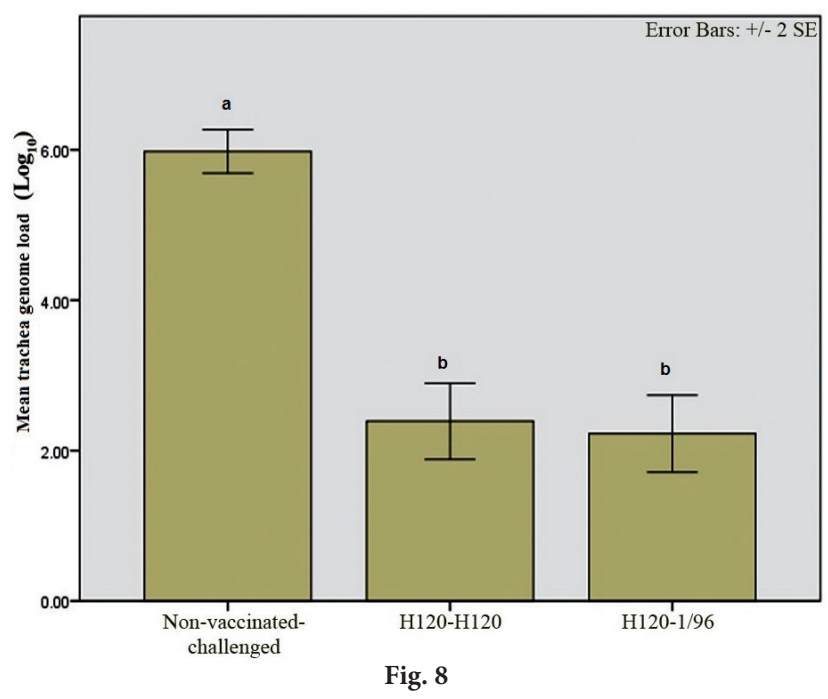

Real-time PCR of tracheal viral load

Viral load detection in the trachea of the SPF chickens, non-vaccinated, vaccinated with $\mathrm{H} 120-\mathrm{H} 120$ or H120-1/96 and challenged with IS/1484-like IBV isolate, after 5 days post challenge. There was a significant difference $(\mathrm{P}<0.05)$ between non-vaccinated-challenged group with other groups, with prominent decrease of viral replication in vaccinated groups (H120H120 and H120-1/96) (a,b).

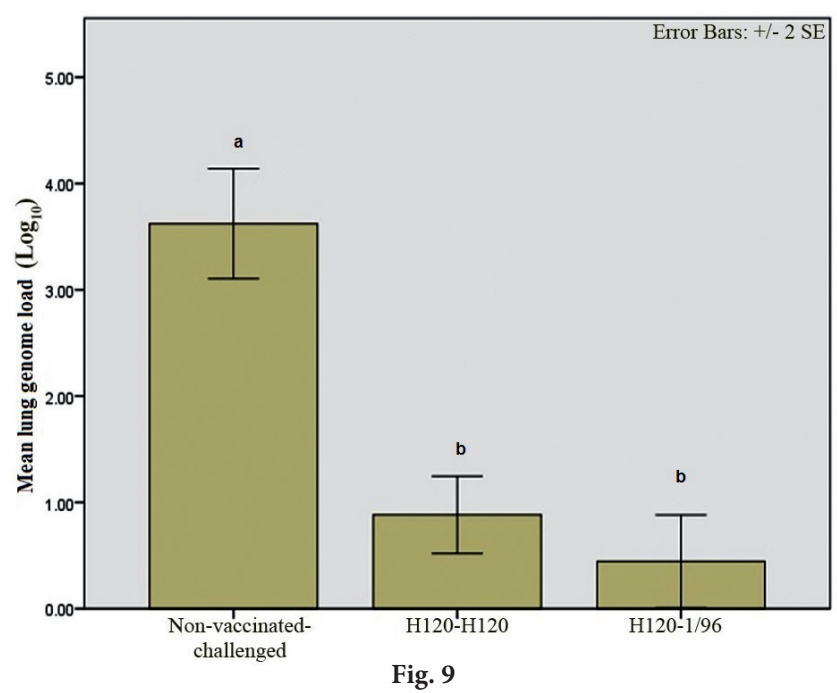

Real-time PCR of lungs viral load

Viral load detection in the lungs of the SPF chickens, non-vaccinated, vaccinated with H120-H120 or H120-1/96 and challenged with IS/1484-like IBV isolate, after 5 days post challenge. There was a significant difference $(\mathrm{P}<0.05)$ between non-vaccinated-challenged group with other groups, with prominent decrease of viral replication in vaccinated groups (H120-H120 and $\mathrm{H} 120-1 / 96)$. Non-significant $(\mathrm{P}>0.05)$ results were observed between H120-H120 and H120-1/96 vaccinated groups (a,b).

Non-vaccinated-challenged group showed hyperemia, petechia, and mild infiltration of inflammatory (dominantly mononuclear) cells. The only findings of pathological exami-

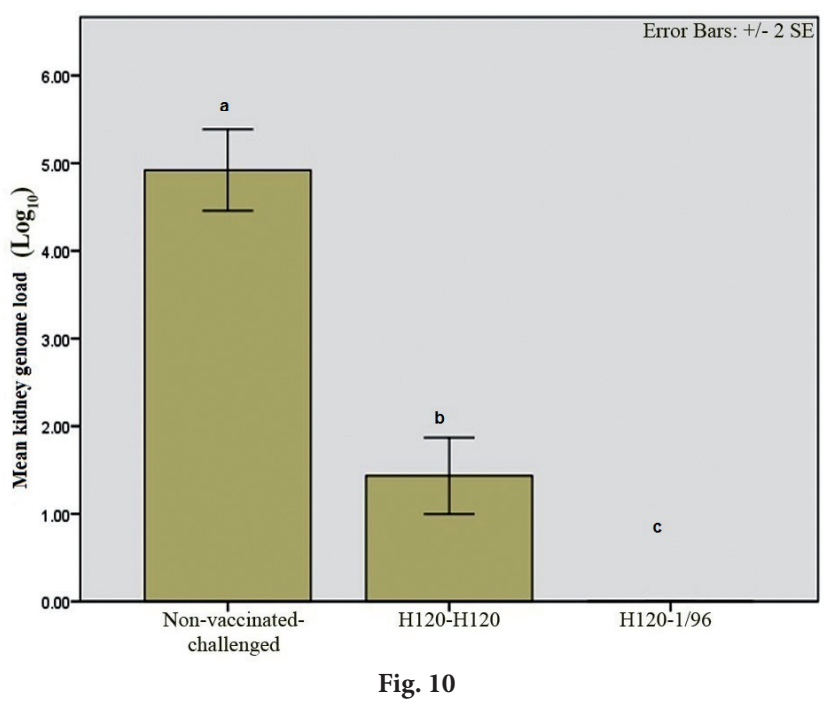

Real-time PCR of kidney viral load

Viral load detection in the kidneys of the SPF chickens, non-vaccinated, vaccinated with $\mathrm{H} 120-\mathrm{H} 120$ or H120-1/96 and challenged with IS/1484-like IBV isolate, after 5 days post challenge. Significant $(\mathrm{P}<0.05)$ differences between the groups were obvious, in which the group receiving H120-1/96 vaccines showed no replication of the challenge virus, although lower and significant $(\mathrm{P}<0.05)$ viral replication can be observed in H120-120 vaccinated group compared to non-vaccinated-challenged group $(\mathbf{a}, \mathbf{b}, \mathbf{c})$.

nation in vaccinated groups were mild hyperemia with no lesions in H120-H120 and H120-1/96 groups (Fig. 6). Kidney results evaluation showed almost the same results as in lungs. Hyperemia and petechial, mild infiltration of inflammatory cells, predominantly mononuclear cells, in interstitial tissue was recorded in non-vaccinated-challenged group, whereas mild hyperemia with no lesions in most samples was the only finding in vaccinated groups (Fig. 7).

\section{Quantitative real-time RT-PCR}

Mean viral load of virus in trachea, lungs, and kidneys is shown in Fig. 8, 9, and 10. Tracheal investigation on challenged virus in all groups showed significant differences $(\mathrm{P}<0.05)$ between non-vaccinated-challenged group compared to H120-H120 and H120-1/96 groups, but no significant difference was detected between H120-H120 and H120-1/96

Table 3. The average of challenge IBV viral loads in trachea, lungs and kidneys

\begin{tabular}{lccc}
\hline Groups & Trachea & Lungs & Kidneys \\
\hline 1 & 0 & 0 & 0 \\
2 & $1.62 \times 10^{6}$ & $1.53 \times 10^{4}$ & $2.83 \times 10^{5}$ \\
3 & $1.5 \times 10^{3}$ & 30.3 & 190 \\
4 & 503 & 102 & 0 \\
\hline
\end{tabular}


groups. Regarding lung viral load, exactly the same levels of differences were detected between the groups which showed the same levels of protection obtained by immunization in H120-H120 and H120-1/96 groups. Viral loads in kidney samples of all groups showed significant differences with the best results detected in H120-1/96 group (Table 3).

\section{Discussion}

In recent years, the Iranian poultry industry has experienced an increasing incidence of respiratory and nephritis problems with severe economic losses related to IB in flocks. The emergence of new IBV variants has caused several problems to design a proper vaccination program (Liu et al., 2006a). However, the development of vaccines against new IBV variants is not generally an ideal option (Bijlenga et al., 2004; Jackwood et al., 2003). Some IBV vaccine strains from a specific serotype may provide protection against some IBV strains of different serotypes (Cook et al., 1999). Therefore, protection studies on new IBV variants could be a helpful method in control strategy of IBV, as it provides information about the efficacy of available commercial vaccines.

To date, the Mass strains have been primarily used as live vaccines due to their epizootic distributions and cross-protective potency (Bijlenga et al., 2004; Ignjatović and Sapats, 2000). Despite the widespread use of IBV vaccines, outbreaks related to different serotypes of IBV have increased in many countries (Li and Yang, 2001; Liu et al., 2006b). On the other hand, the reported persistence of the Israeli variant isolate (IS/1494/06) related problems in spite of vaccinations of the broiler flocks with $\mathrm{H} 120$, supports the argument of IS/1494/06 IBV presence in the Middle East countries (Mahmood et al., 2011; Meir et al., 2004). A pair wise comparison of the S1 gene sequences of IS/1494/06like viruses showed low level of identity to the Mass $(81 \%$ percent identity to $\mathrm{H} 120$ ) and 793/B (80\% identity to CR88) type viruses (Awad et al., 2014). In this study, we used two different IBV serotypes (H120 and 1/96 (79/B-like)) in order to evaluate their combined effect as protectotypes against IBV IS/1494/06-like viruses.

Vaccination against IBV has been practiced for over half a century. Besides commercial vaccines of Mass serotype, 793/B serotype vaccines have been produced by several companies including 4/91 (Intervet), IB88 (Merial), IBird (Ceva Santé Animale), 233A (Phibro). TAbic IB VAR206 also has been produced as variant 2 vaccine (IS/1494/06 origin) by Phibro. Mass and 793B type vaccines (4/91 and IB88) are main serotypes used in Iran (Cavanagh et al., 2005; Seyfi Abad Shapouri et al., 2004).

In the present study, for the vaccine program we have selected combination of Mass (H120) and 793/B (1/96 strain) serotypes. The usage of both Mass (H120) and 793/B (1/96) in vaccination program makes a broader range of protection against different serotypes of IBV found worldwide (Cavanagh et al., 1999), as observed with different evaluation methods that group receiving H120-1/96 vaccines showed almost the best results among all groups. In our study, the vaccines were administered by eye drop route on $1^{\text {st }}$ and $14^{\text {th }}$ day and since acceptable protection can be frequently seen using suggested protocol (Cook et al., 1999), we have expected the reliable results.

SPF chickens were used in these studies, although, under commercial conditions, it is likely that day old chicks would have maternally derived IBV antibodies. However, earlier studies (Davelaar and Kouwenhoven, 1977) have shown that it is possible to vaccinate successfully even if such antibodies are present. As it is shown in the present study, using vaccine with two serotypes (H120-1/96 group) resulted in a better cross protection (69.2\% compared to $60 \%$ protection) as previously confirmed (Cook et al., 1999; Davelaar and Kouwenhoven, 1977).

Our results are consistent with a recent study done in Israel with 1494/06 virus challenge which revealed $70 \%$ of cilliary protection in $\mathrm{H} 120$ (day 0) +793/B (day 14) vaccinated group. They also reported $83 \%$ and $95 \%$ protection in chickens vaccinated with 793/B+793/B and Var206+Var206, respectively. It is obvious that homologous challenge-vaccination study (challenge with 1494/06 and vaccination with Var206 vaccine) leads to a higher protection level. Despite the previously mentioned variation (19-21\%) in S1 gene of the IS/1494/06-like viruses with $\mathrm{H} 120$ and 793/B viruses, the successful protection conferred by our vaccination program may be attributed to the shared characteristics of the $S 1$ protein of the vaccine and challenged IBVs (Cavanagh et al., 1986). A new study has been conducted by Awad (Awad et al., 2015) obtaining almost the same results as we have, in which the group receiving $\mathrm{H} 120$ vaccine (1 day old) and 793/B vaccine (14 days old) showed $80 \%$ protection of cilia against challenge with IS/1494/06like virus. They also evaluated vaccination program using H120 and 793/B vaccine (day 1) and 793/B vaccine (day 14) against same challenge virus. The results showed $94 \%$ of protection. They concluded that, the combination of these vaccines confers acceptable protection against heterologous challenge. Higher protection of this vaccination program (day 0: H120+793/B and day 14: 793/B) could be due to the higher level of local and cellular immunity at the tracheal site (Lambrechts et al., 1993), in which it has been shown that using both serotype vaccines (H120 and 793/B) in day old chickens induces significant increase in the expression of CD4+, CD8+ and IgA-bearing B cells in the trachea compared with single H120 vaccination (Awad et al., 2014).

In a study by De Wit et al. (2011) on commercial broiler breeders, it was reported that Mass (day 0) + 793/B (day 14) vaccines combination and challenge with D388 (QX genotype) after 28 days produced $51 \%$ protection in cilliostasis 
test 5 days post challenge, while the protection increased to $74 \%$ on $7^{\text {th }}$ day after challenge.

Despite the proper protection conferred by Mass and 793/B vaccines against IS/1494/06, there was a study showing challenge with IS/1494/06 Israel 2 variant after vaccination with a Mass-type vaccine followed by QX-like vaccine 14 days later which conferred $50 \%$ protection of the vaccinated birds. In vaccinology of IBV, it is important to note that vaccines' efficacy is based on its ability to control cilliostasis caused by the challenge virus. Median clinical sign scores and challenge virus load in different organs also showed the same results considering a better protection of vaccinated groups. These findings are consistent with Cook et al. (1976) demonstrating an improved protection that can be achieved after the challenge with many different serotypes using a program of combined serotype vaccine with antigenically different IBV strains incorporated (Adzhar et al., 1995).

It should be noted that in cross-protection experiment, even in closely controlled experimental situations, $10 \%$ of vaccinated chicks would not respond with a protective immune response against challenge with the homologous strain (Cook et al., 1996; Nix et al., 2000; Winterfield et al., 1976). These results show that chickens (out-bred, though with restricted sets of parental breeding stocks) are not uniform in their response to IBV vaccination.

The real-time PCR technique is frequently used for IB infections diagnostics (Cook et al., 1996). To evaluate vaccination ability to control challenge virus, the quantitative real-time PCR was examined for trachea, kidney and lung tissue samples. Titers of the live virus are usually maximal in the nose and trachea within three days and remain so for 2 to 5 days further (Hofstad and Yoder, 1966).

In our findings, although there was no statistically significant difference between H120-H120 and H120-1/96 groups, the results showed that lowest viral load was observed in H120-1/96 vaccinated group and significant virus replication control was recorded between vaccinated and non-vaccinated groups.

In our study, there was no challenge virus detected in the kidneys of H120-1/96 vaccinated group. These results may be due to the ability of vaccines in controlling virus replication in the kidneys comparing to non-vaccinatedchallenged group.

It has been reported that low level of IBV replication in the kidney, using combined (H120-1/96) vaccines is due to the low level of virus replication in the trachea and also higher antibody level of the vaccinated birds (Lambrechts et al., 1993), which decreases possibilities of virus replication in the kidneys. Somehow, this finding could be very important in the field conditions as lots of nephrotoxic factors such as high protein and calcium diet, mycotoxins, drugs such as sulfonamides, cold stress, nephropathic diseases, and some other factors can affect flock performance and mortality which can be impressed by IBV presence in the kidneys. The same results were also recorded for lung samples $(3.03 \mathrm{E}+01$ and 1.02E+02 compared to $1.53 \mathrm{E}+04$ ).

Histopathological evaluation of tracheal samples showed significant differences between non-challenged group (negative control) with H120-H120 and H120-1/96 group, while there were no significant differences between negative control and H120-1/96 vaccinated groups which showed the protective effect against $\mathrm{H} 120$ and 1/96 strains combination and limited pathological damages of the trachea.

Trachea lesions in IBV infected birds is often critical in poultry flocks especially in broiler flocks that are dealing with unsuitable conditions such as high ammonia, IBVs dust, $\mathrm{CO}_{2}$, and several respiratory diseases. Comparison of histopathological lesions between vaccinated and nonvaccinated-challenged groups revealed that vaccination was effective to control the viral related lesions such as severe hyperemia or petechia in the lungs, and lower median pathological score in the trachea.

It is known that under some conditions, which are yet poorly defined, some strains of IBV apparently are able to induce nephrosis (Winterfield and Hitchner, 1962; Zanella, 1988). It is proved that the Mass-like vaccines used alone usually provided poor protection against the nephritis caused by nephrotropic viruses (Cook et al., 2001). As it is observed in present study, vaccination program in H120-H120 could not completely prevent virus replication in kidneys, but as previous reports (Cook et al., 2001) and our findings show combination of H120 and 793/B (1/96) vaccination program could protect chicken from nephritis. Overall, in histopathological evaluation of kidney samples almost no damage was recorded for vaccinated groups (H120-H120 and H120-1/96 groups) showing only very mild hyperemia. In this research, ELISA was used to measure antibody titers against IBV. ELISA detected high levels of antibody against IBV 21 days after last vaccination. Ghadakchi et al. (2005) showed that ELISA could be reliable, repeatable and sensitive for monitoring vaccination schedules and the rapid detection of the early rise of antibodies against IBV. These results were consistent with Susan et al. (2011).

Our results show that vaccination using two serotypes (H120-1/96) can lead to a better immune response. It also indicates that GMT of H120-1/96 group (GMT: 1960) is significantly higher than H120-H120 group (GMT: 1064). It is believed that cytotoxic T cells play an important anti-viral activity role during early stages of IBV infection while serum IgG is critical at the late stage of IBV infection (Collisson et al., 2000). Therefore, obtaining higher antibody level using combined (H120 and 1/96 strains) vaccination program will surely control IBV infection in the flock.

These results definitely show the important role of 1/96 strain (793/B group) in vaccination program to control IBV infection, especially 1494/06-like IB viruses which are domi- 
nant circulating IBVs in commercial flocks in Iran. However, more studies are needed on vaccination policies to control IBV infections in Iranian poultry farms.

Acknowledgement. The authors gratefully acknowledge Mr. Behrooz Asadi and Mr. Javanmardi for their extensive technical supports. This study was conducted under grant of research council, University of Tehran (No. 28692/6/1). The main grant source (No. 93189) for doing the project was supplied by Ceva Santé Animale, Iran, Savapars (exclusive distributor in Iran). In addition, Iranian veterinary organization under grant (No. 22/39007) financially supported this project.

\section{References}

Adzhar A, Shaw K, Britton P, Cavanagh D (1995): Avian infectious bronchitis virus: differences between $793 / \mathrm{B}$ and other strains. Vet. Record 136, 548-548. https://doi. org/10.1136/vr.136.21.548-a

Aghakhan S, Abshar N, Fereidouni SRN, Marunesi C, Khodashenas M (1994): Studies on avian viral infections in Iran. Archives de l'Institut Razi, 1-10.

Akbari Azad G, Vasfi Marandi M, Keyvani Aminae H (2007): Molecular analysis of three Iranian isolates belonged to 793/B serotype of Infectious bronchitis viruses. J. Vet. Res 62, 69-80.

Awad F, Baylis M, Ganapathy K (2014): Detection of variant infectious bronchitis viruses in broiler flocks in Libya. Int. J. Vet. Sci. Med. 2, 78-82. https://doi.org/10.1016/j. ijvsm.2014.01.001

Awad F, Forrester A, Baylis M, Lemiere S, Ganapathy K, Hussien HA, Capua I (2015): Protection conferred by live infectious bronchitis vaccine viruses against variant Middle East IS/885/00-like and IS/1494/06-like isolates in commercial broiler chicks. Vet. Rec. Open 2, e000111. https:// doi.org/10.1136/vetreco-2014-000111

Bande F, Arshad SS, Hair Bejo M, Moeini H, Omar AR (2015): Progress and challenges toward the development of vaccines against avian infectious bronchitis. J. Immunol. Res. 424860. https://doi.org/10.1155/2015/424860

Bijlenga G, Cook JK, Gelb J Jack, Wit JD (2004): Development and use of the $\mathrm{H}$ strain of avian infectious bronchitis virus from the Netherlands as a vaccine: a review. Avian Pathol. 33, 550-557. https://doi.org/10.1080/03079450400013154

Callison SA, Hilt DA, Boynton TO, Sample BF, Robison R, Swayne DE, Jackwood MW (2006): Development and evaluation of a real-time Taqman RT-PCR assay for the detection of infectious bronchitis virus from infected chickens. J. Virol. Methods 138, 60-65. https://doi.org/10.1016/j. jviromet.2006.07.018

Cavanagh D (1996): Nidovirales: a new order comprising Coronaviridae and Arteriviridae. Arch. Virol. 142, 629-633.

Cavanagh D (2005): Coronaviruses in poultry and other birds. Avian Pathol. 34, 439-448. https://doi. org/10.1080/03079450500367682
Cavanagh D, Davis PJ, Darbyshire JH, Peters RW (1986): Coronavirus IBV: virus retaining spike glycopolypeptide S2 but not $\mathrm{S} 1$ is unable to induce virus-neutralizing or haemagglutination-inhibiting antibody, or induce chicken tracheal protection. J. Gen. Virol. 67, 1435-1442. https:// doi.org/10.1099/0022-1317-67-7-1435

Cavanagh D, Elus M, Cook J (1997a): Relationship between sequence variation in the $\mathrm{S} 1$ spike protein of infectious bronchitis virus and the extent of cross-protection in vivo. Avian Pathol. 26, 63-74. https://doi. org/10.1080/03079459708419194

Cavanagh D, Elus MM, Cook JK (1997b): Relationship between sequence variation in the S1 spike protein of infectious bronchitis virus and the extent of crossprotection in vivo. Avian Pathol. 26, 63-74. https://doi. org/10.1080/03079459708419194

Cavanagh D, Mawditt K, Britton P, Naylor C (1999): Longitudinal field studies of infectious bronchitis virus and avian pneumovirus in broilers using type-specific polymerase chain reactions. Avian Pathol. 28, 593-605. https://doi. org/10.1080/03079459994399

Cavanagh D, Picault J-P, Gough RE, Hess M, Mawditt K, Britton P (2005): Variation in the spike protein of the 793/B type of infectious bronchitis virus, in the field and during alternate passage in chickens and embryonated eggs. Avian Pathol. 34, 20-25. https://doi.org/10.1080/03079450400025414

Chen B, Hosi S, Nunoya T, Itakura C (1996): Histopathology and immunohistochemistry of renal lesions due to infectious bronchitis virus in chicks. Avian Pathol. 25, 269-283. https://doi.org/10.1080/03079459608419141

Collisson EW, Pei J, Dzielawa J, Seo SH (2000): Cytotoxic T lymphocytes are critical in the control of infectious bronchitis virus in poultry. Develop. Comp. Immunol. 24, 187-200. https://doi.org/10.1016/S0145-305X(99)00072-5

Cook J, Orbell S, Woods M, Huggins M (1996): A survey of the presence of a new infectious bronchitis virus designated 4/91 (793B). Vet. Rec. 138, 178-180. https://doi.org/10.1136/ vr.138.8.178

Cook JK, Chesher J, Baxendale W, Greenwood N, Huggins MB, Orbell SJ (2001): Protection of chickens against renal damage caused by a nephropathogenic infectious bronchitis virus. Avian Pathol. 30, 423-426. https://doi. org/10.1080/03079450120066421

Cook JK, Darbyshire J, Peters R (1976): The use of chicken tracheal organ cultures for the isolation and assay of avian infectious bronchitis virus. Arch. Virol. 50, 109-118. https:// doi.org/10.1007/BF01318005

Cook JK, Orbell SJ, Woods MA, Huggins MB (1999): Breadth of protection of the respiratory tract provided by different live-attenuated infectious bronchitis vaccines against challenge with infectious bronchitis viruses of heterologous serotypes. Avian Pathol. 28, 477-485. https://doi. org/10.1080/03079459994506

Davelaar F, Kouwenhoven B (1977): Influence of maternal antibodies on vaccination of chicks of different ages against infectious bronchitis. Avian Pathol. 6, 41-50. https://doi. org/10.1080/03079457708418211 
De Wit J, Guerrero P, Calvo J, Hidalgo H, Lierz M, Heffels-Redmann U, Kaleta E, Heckmann J (2012): Report of the genotyping, pathotyping, and protectotyping of recent strains from Chile. VII. International Symposium on Avian Corona-and Pneumoviruses and Complicating Pathogens. Rauischholzhausen, Germany, 18-21 June 2012, pp. 61-67.

Gelb Jr J, Weisman Y, Ladman BS, Meir R (2005): S1 gene characteristics and efficacy of vaccination against infectious bronchitis virus field isolates from the United States and Israel (1996 to 2000). Avian Pathol. 34, 194-203. https:// doi.org/10.1080/03079450500096539

Gelb Jr J, Wolff J, Moran C (1991): Variant serotypes of infectious bronchitis virus isolated from commercial layer and broiler chickens. Avian Dis. 82-87. https://doi. org/10.2307/1591298

Ghadakchi H, Dadras H, Pourbakhsh S, Hosseini S (2005): Standardization of an enzyme-linked immunosorbent assay for detection of infectious bronchitis virus antibody. Arch. Razi 59, 75-83.

Ghahremani N, Fard MB, Shoushtari H, Momayez R, Sheikhi N, Khoshzahmat A, Eshratabadi F (2011): Molecular analysis of infectious bronchitis viruses isolated in Iran from 19982008. J. Anim. Vet. Adv. 10, 2961-2967.

Hofstad M, Yoder HW (1966): Avian infectious bronchitis: Virus distribution in tissues of chicks. Avian Dis. 10, 230-239. https://doi.org/10.2307/1588355

Hosseini H, Bozorgmehri Fard MH, Charkhkar S, Morshed R (2015): Epidemiology of avian infectious bronchitis virus genotypes in Iran (2010-2014). Avian Dis. 59, 431-435 https://doi.org/10.1637/11091-041515ResNote. 1

Hussein AH, Emara M, Rohaim M, Ganapathy K, Arafa A (2014): Sequence analysis of infectious bronchitis virus IS/1494 like strain isolated from broiler chicken co-infected with Newcastle disease virus in Egypt during 2012. Int. J. Poult. Sci. 13, 530-536. https://doi.org/10.3923/ ijps.2014.530.536

Ignjatović J, Sapats S (2000): Avian infectious bronchitis virus. Revue scientifique et technique (International Office of Epizootics) 19, 493-508. https://doi.org/10.20506/ $\underline{\text { rst.19.2.1228 }}$

Jackwood, MW (2012): Review of infectious bronchitis virus around the world. Avian Dis. 56, 634-41. https://doi. org/10.1637/10227-043012-Review.1

Jackwood MW, Hilt DA, Brown TP (2003): Attenuation, safety, and efficacy of an infectious bronchitis virus GA98 serotype vaccine. Avian Dis. 47, 627-632. https://doi. org $/ 10.1637 / 6094$

Jackwood, MW, Hilt, DA, Callison, SA, Lee, CW, Plaza, H, Wade E (2001): Spike glycoprotein cleavage recognition site analysis of infectious bronchitis virus. Avian Dis. 45, 366-72. https://doi.org/10.2307/1592976

Kahya S, Coven F, Temelli S, Eyigor A, Carli KT (2013): Presence of IS/1494/06 genotype-related infectious bronchitis virus in breeder and broiler flocks in Turkey. Ankara Üniv. Vet. Fak. Derg. 60, 27-31. https://doi.org/10.1501/ Vetfak 0000002549
Kusters J, Niesters H, Lenstra J, Horzinek M, Van Der Zeijst B (1989): Phylogeny of antigenic variants of avian coronavirus IBV. Virology 169, 217-221. https://doi. org/10.1016/0042-6822(89)90058-5

Lambrechts C, Pensaert M, Ducatelle R (1993): Challenge experiments to evaluate cross-protection induced at the trachea and kidney level by vaccine strains and Belgian nephropathogenic isolates of avian infectious bronchitis virus. Avian Pathol. 22, 577-590. https://doi. org/10.1080/03079459308418945

Li H, Yang H (2001): Sequence analysis of nephropathogenic infectious bronchitis virus strains of the Massachusetts genotype in Beijing. Avian Pathol. 30, 535-541. https:// doi.org/10.1080/03079450120078734

Liu S, Chen J, Han Z, Zhang Q, Shao Y, Kong X, Tong G (2006a): Infectious bronchitis virus: $S 1$ gene characteristics of vaccines used in China and efficacy of vaccination against heterologous strains from China. Avian Pathol. 35, 394-399. https://doi.org/10.1080/03079450600920984

Liu S, Zhang Q, Chen J, Han Z, Liu X, Feng L, Shao Y, Rong J, Kong $X$, Tong G (2006b): Genetic diversity of avian infectious bronchitis coronavirus strains isolated in China between 1995 and 2004. Arch. Virol. 151, 1133-1148. https://doi. org/10.1007/s00705-005-0695-6

Mahmood ZH, Sleman RR, Uthman AU (2011): Isolation and molecular characterization of Sul/01/09 avian infectious bronchitis virus, indicates the emergence of a new genotype in the Middle East. Vet. Microbiol. 150, 21-27. https://doi.org/10.1016/j.vetmic.2010.12.015

Meir R, Rosenblut E, Perl S, Kass N, Ayali G, Hemsani E, Perk $S$ (2004): Identification of a novel nephropathogenic infectious bronchitis virus in Israel. Avian Dis. 48, 635-641. https://doi.org/10.1637/7107

Mockett AA, Cavanagh D, Brown TDK (1984): Monoclonal antibodies to the S1 spike and membrane proteins of avian infectious bronchitis coronavirus strain Massachusetts M41. J. Gen. Virol. 65, 2281-2286. https://doi. org/10.1099/0022-1317-65-12-2281

Nakamura K, Cook JK, Otsuki K, Huggins MB, Frazier JA (1991): Comparative study of respiratory lesions in two chicken lines of different susceptibility infected with infectious bronchitis virus: histology, ultrastructure and immunohistochemistry. Avian Pathol. 20, 241-257. https://doi. org/10.1080/03079459108418761

Nix W, Troeber D, Kingham B, Keeler Jr C, Gelb Jr J (2000): Emergence of subtype strains of the Arkansas serotype of infectious bronchitis virus in Delmarva broiler chickens. Avian Dis. 568-581. https://doi.org/10.2307/1593096

Raj GD, Jones R (1996): Protectotypic differentiation of avian infectious bronchitis viruses using an in vitro challenge model. Vet. Microbiol. 53, 239-252. https://doi.org/10.1016/ $\underline{\mathrm{S} 0378-1135(96) 01258-8}$

Seyfi Abad Shapouri M, Mayahi M, Assasi K, Charkhkar S (2004): A survey of the prevalence of infectious bronchitis virus type 4/91 in Iran. Acta Vet. Hung. 52, 163-166. https:// doi.org/10.1556/AVet.52.2004.2.4

Sjaak de Wit JJ, Cook JK, van der Heijden HM (2011): Infectious bronchitis virus variants: a review of the history, current 
situation and control measures. Avian Pathol. 40, 223235. https://doi.org/10.1080/03079457.2011.566260

Susan S, El-Hady M, Soliman Y (2010): Isolation and characterization of nephropathogenic strain of infectious bronchitis virus in Egypt. J. Am. Sci. 6, 669-675.

Susan S, YA S, MM E-H (2011): Preparation and evaluation of master seed for infectious bronchitis vaccine from local variant isolate. Nat. Sci. 9, 145-150.

Winterfield R, Fadly A, Hoerr F (1976): Immunity to infectious bronchitis virus from spray vaccination with deriva- tives of a Holland strain. Avian Dis. 42-48. https://doi. org/10.2307/1589472

Winterfield R, Hitchner S (1962): Etiology of an infectious nephritis-nephrosis syndrome of chickens. Am. J. Vet. Res. 23, 1273.

Zanella A (1988): Avian infectious bronchitis: properties and application of attenuated vaccine prepared with nephropathogenic strain AZ-23/74. Proc. International Symposium on Infectious Bronchitis. Rauischholzhausen, Germany, pp. 335-342. 